\title{
Phonetic Complexity and Stuttering in Turkish-Speaking Children who Stutter
}

\begin{abstract}
The relationship between stuttering and phonetic complexity for words spoken by Turkish children who stutter was investigated. The research questions were: (1) Do Turkishspeaking children stutter more on unbound content words than on unbound function words? (2) Do Turkish-speaking children stutter more on words with higher phonetic complexity scores? Twenty-one monolingual children aged 6-11 years who had a clinical diagnosis of stuttering participated. Speech samples were transcribed and lexical categories determined. Phonetic complexity was assessed by an adaptation of Jakielski's (1998) Index of Phonetic Complexity (IPC) for Turkish. Results revealed that the mean rank of unbound content words differed significantly from the mean rank of unbound function words and that stuttering frequency for unbound content words was significantly higher than for unbound function words.
\end{abstract}

Keywords: stuttering; Turkish; phonetic complexity; lexical category 


\section{Introduction}

Stuttering is a complex disorder in which the forward flow of an individual's speech is interrupted (Bloodstein \& Grossman, 1981). Although the precise mechanisms underlying stuttering are not fully understood, recent models suggest that many constitutional (hereditary and neurobiological) and environmental (psychological, linguistic and social) factors contribute to its emergence and development (Smith, 1999). Biological influences during language development affect the likelihood that stuttering may develop (Smith, 1999), whilst other influences serve a situational role and affect the likelihood of stuttering occurring on a given word or place in an utterance (Howell \& $\mathrm{Au}-$ Yeung 2002).

Linguistic factors are among situational factors that affect the probability of stuttering occurring on a particular word in an utterance. The relationship between stuttering and situational linguistic factors like word length, word familiarity, phonetic stress, initial sound of the word, position in an utterance, grammatical complexity and speaking rate have been studied extensively for English (Au-Yeung, Howell \& Pilgrim, 1998; Howell, Au-Yeung \& Sackin, 1999; Logan, 2001; Silverman \& Bernstein Ratner, 1997) subsequent to Brown's seminal work in this area (Brown, 1945). One situational linguistic factors is whether the words are function or content in type (Brown, 1937). Research on adults who stutter (AWS) suggest that they experience more problems dealing with content (C) than function words (F) (Brown, 1937; Howell, Au-Yeung \& Sackin, 2000; Howell, Au-Yeung, Yaruss \& Eldridge 2006). In contrast, children who stutter show more problems on Fs than Cs (Bloodstein \& Gantwerk to adults, 1967; Bloodstein \& Grossman, 1981).

Howell, Au-Yeung and Sackin's (1999) analysis of English spontaneous speech revealed that Fs differed from Cs phonologically. In comparison with Fs, Cs are 
multisyllabic more often, carry primary stress and frequently start with developmentally late-emerging consonants and consonant strings. Cs carry semantic information that add extra pressure on the time needed for words to be planned and executed (Howell \& AuYeung, 2002). Other early studies investigated phonetic complexity of the dysfluent words in AWS in languages, such as German, which have similar structure to English (Dworzynski, Howell, Au-Yeung \& Rommel, 2004) and reported similar findings. Note that what other researchers' term phonetic complexity has replaced the term phonological complexity in recent studies (Coalson, Byrd \& Davis, 2012; Byrd, Coalson, Yang \& Moriarty, 2017). Eldrige (2006) noted that the two terms are used interchangeably across different studies insofar as they are based on index of phonetic complexity (IPC) to measure complexity. Whilst phonetic complexity is often confused with phonological complexity (Eldridge, 2006), Marchal (2011) stated that levels related to phonemes, syllables, consonantal sequences and dimensions covering cognitive load and execution are embraced within the concept of phonetic complexity. As a primary metric used by researchers to measure complexity, IPC provides an aggregated complexity score based on phonetic properties (Byrd et al. 2017). In the current study, phonological complexity builds on distinctive binary features of segments (Maddieson, 2009). However, the spatio-temporal physical realization of these phonological distinctive features emerges in phonetics (Chitoran \& Cohn, 2009). Hence, the term phonetic complexity is used in the current study in the sense of the number of complex attributes manifested in the index of phonetic complexity required to accurately produce a target word. An increase in these complex attributes is related to an increased probability of disfluency.

The reasons for the change from stutters on $\mathrm{F}$ to stutters on $\mathrm{C}$ across age groups for in English were addressed by EXPLAN theory (Howell, 2004; Howell \& Rusbridge, 2011). EXPLAN maintains that two forms of speech breakdown occur, one that occurs 
frequently in early development (stutters on Fs) and the other happens more often in adulthood (stutters on Cs). The reasons for the two different forms is revealed when speech is segmented into prosodic words (Selkirk, 1984). Prosodic words (PW) ${ }^{1}$ in English consist of an obligatory $\mathrm{C}$ that can have an arbitrary number of $\mathrm{F}$ preceding and following it (FnCFm, where $\mathrm{n}$ and $\mathrm{m}$ take integer values from zero upwards). The source of problems in a PW like "he spilt it" (FCF) is always the C which is usually the most phonetically complex word. Young children tend to tackle this problem by delaying their attempt at the $\mathrm{C}$ by pausing before, or repeating, the initial $\mathrm{F}$ word/s until they have the plan ready to attempt the $\mathrm{C}$ (stalling). AWS use this form of delaying less often that leads them to attempt Cs before their plan is complete (advancing). This results in disfluencies on the first part of Cs including part-word repetitions and prolongations (Howell \& Akande, 2005).

The role of phonetic complexity is essential to the EXPLAN model (Howell \& Rusbridge, 2011). The increased phonetic complexity going from an initial F, to the following $\mathrm{C}$ in a $\mathrm{PW}$ is what leads to the stalling and advancing patterns of stuttering. For English and related languages, $\mathrm{F}$ and $\mathrm{C}$ is a convenient way of dividing words into phonetically complex, C, less complex (C) and less complex (F) within the context of a PW phonological unit (Howell \& Dworzynski, 2005). The variation in complexity affects

\footnotetext{
${ }^{1}$ In the present study abbreviations below are used:

AWS : adults who stutter

C : content word

Cunbound : unbound content word

CM : content morpheme

CWS : children who stutter

$\mathrm{F} \quad$ : function word

Funbound : : unbound function word

FM : function morpheme

IPC : index of phonetic complexity

PW : prosodic word
} 
speech planning, prior to execution, and can lead to plans for Cs not being completed at the time when they need to be produced. Consequently, moments of stuttering are precipitated. Different linguistic, e.g. syntactic, lexical, phonetic, and prosodic levels are included in the planning process (Howell, 2004a, b). Planning and execution processes are independent and are staggered in time (Howell \& Dworzynski, 2005). Hence, planning of a forthcoming segment can start whilst the current segment is being executed. Whereas the initial $\mathrm{F}$ to $\mathrm{C}$ transition in a PW often entails an abrupt change in complexity leading to the different patterns of stuttering at different ages for English, Turkish would lead to different complexity influences on different word types that would change the impact on stuttering rates relative to English.

Subsequent work on EXPLAN has investigated Spanish (Howell \& Au-Yeung, 2007), Japanese (Smith \& Howell, 2013), Persian (Vahab, Zandiyan, Falahi \& Howell, 2013) and Arabic (Al-Tamimi, Khamaiseh \& Howell, 2013). The properties of Cs and Fs in these languages differ markedly from English. In English and most other IndoEuropean languages, Fs are phonetically less complex, and occur more frequently than Cs which would make them easy to process as supported by their early occurrence in the speech of children. In contrast, Fs are usually phonetically simpler and carry restricted on the information (Dayalu, Kalinowski, Stuart, Holbert \& Rastatter 2002). Studies on languages where Fs lead to them being processed differently from English and related languages give the opportunity to test the hypotheses of the EXPLAN model. The structure of Turkish differs in several important ways from English. Turkish is an agglutinative language (Acarlar \& Johnston, 2011), and suffixation is the most common word formation style in this language. Suffixation occurs by attaching derivational and inflectional morphemes to stems. What is also peculiar to Turkish as an agglutinative language is that it has the potential to generate words of arbitrary length. Most European 
languages that examined phonetic complexity within the framework of EXPLAN include word length as a factor independent of word type.

Although EXPLAN employs Fs and Cs to explain the pattern of developmental changes in stuttering for English, their essential property that associates them with stalling and advancing is that they dissociate phonetically-simple material (initial Fs in PWs) that precede phonetically-complex material (e.g. Cs that often have complex onset clusters) (Howell \& Rusbridge, 2011). Final Fs in PW (CF) do not lead to stalling according to EXPLAN which: (1) shows that Fs per se do not trigger stalling-type dysfluencies; and (2) allows predictions to be made about forms of stuttering for languages like Japanese (Ujihira, 2011) and Turkish that have functors that are bound to $C$ stems as suffixes (Howell \& Rusbridge, 2011). The general goal of the present work is to establish how the structure of the Turkish language affects patterns of stuttering to evaluate EXPLAN: To this end, background on taxonomy of word types and measurement of phonetic difficulty for Turkish follow.

\section{Characteristics of the Turkish Language}

Turkish is an agglutinative language which belongs to the Altaic branch of the Ural-Altaic family. Derivational and inflectional morphemes are added at the end of the root so as to make new words and even sentences in Turkish. For example, an English sentence such as "You should not have come." would be expressed in Turkish as the single word in (1).

(1) gel-me-meli-y-di-n

verb-negative-obligation- epenthetic consonant-past-second person singular You should not have come.

In (1) the negation, obligation, tense and person markers are added as inflectional suffixes to the verb root (gel-) to constitute the one-word sentence. The verb (gel-) itself 
is categorized as an unbound content word $\left(\mathrm{C}_{\text {unbound }}\right)$. The word/sentence starts with $\mathrm{C}$ and has a number of final Fs but no initial Fs that can be used to stall the onset of the C.

\section{Lexical Categories in Turkish}

As stated earlier, Turkish is an agglutinative language, and suffixation is the most common word formation style in the language. Suffixation morphemes (derivational and inflectional) are all bound morphemes in Turkish. C, F and function morpheme (FM), content morpheme $(\mathrm{CM})$ orders may change depending on the morphological structure of the word and the suffix/es in the language. For example, whilst determiners occur before Cs, postpositions occur after Cs in Turkish. In (2), C-CM-FM-FM order is shown for one word (kitapç1larda).

(2) kitap-çı-lar-da

book- derivational suffix- plural-locative

'at the booksellers'

In example (2), the noun kitap 'book' is categorized as $\mathrm{C}_{\text {unbound }}$ and the derivational suffix $\{-\mathrm{C} I\}$ (means $\{-\mathrm{er}\}$ ) is categorized as CM. The rest of the inflectional morphemes are categorized as FM. On the other hand, in (3), için 'for' is a participle (postposition) that is classified as an unbound function word (Funbound) that occurs after

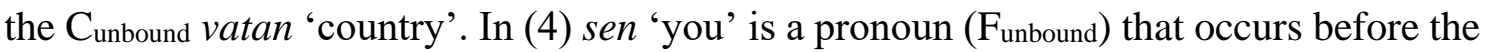
Cunbound verb gel 'come'.

(3) vatan için

country for

'for country'

(4) sen gel.

$2^{\text {nd }}$ singular person-come 
'You come.'

Lexical categories such as nouns, verbs, adjectives and adverbs are classified as lexical words (Cunbounds) whereas derivational suffixes are classified as lexical morphemes $(\mathrm{CM})$, and inflectional suffixes are grammatical morphemes that are categorized as FM (Balc1, 2012, p. 40-45). Table 1 summarizes the classes of Turkish lexical categories that were mentioned above.

Table 1 about here

As shown in Table 1, nouns, verbs, adjectives and adverbs are categorized as $\mathrm{C}_{\text {unbound; }}$ pronouns, conjunctions, determiners, and participles (postpositions) are categorized as Funbound. Examples 1-4 illustrate some of the Turkish C, F, Funbound, $\mathrm{Cunbound}_{\text {, }}$ CMs and FMs that are summarized in Table 1. This classification is a semantic-based classification and the analyses in the current study were made according to this taxonomy.

\section{Index of Phonetic Complexity and Modification for Turkish}

A measure of the phonetic complexity of F, C, FM and CM is needed for Turkish because of the difference noted between this and other languages (several such measures are available for English and other languages to assess complexity differences between word types). Based on earlier work by MacNeillage and Davis (1990), Jakielski (1998) developed a word-based index measure of phonetic complexity for English based on prelinguistic speech outputs of infants (IPC). There are eight factors in the IPC each of which can be used to give a score 0 (not difficult) or 1 (difficult) (Howell et al., 2006). IPC scores of 0 and 1 for each factor are based on whether or not the phonetic form is acquired early. 
For factor 1, "consonant by place class", each dorsal consonant in a word is given one point while other consonants receive no score. The second factor is "consonant by manner class" in which every fricative, affricate and liquid consonant in a word is given one point, while no score is given to other consonants. The third factor is "singleton consonants by place". For this factor, if two consonants have different place classifications, one point is given to that consonant pair. Factor 4 is termed "vowel by class" and rhotics are given one point. Factor 5 is "word shape" and each word that ends with a consonant is given one point. Factor 6 is "word length in syllables" and a word with three or more syllables is given one point and words with less than three syllables receive no points. For factor 7, "contiguous consonants", any consonant string (cluster) is given one point irrespective of the syllable or word position the string occupies. For factor 8 , "cluster by place", if the consonants from a cluster have different places of articulation, one additional point is given (Howell \& Au-Yeung, 2007). Based on these factors, each part of a word composed of any of the eight parameters receives a complexity point. The sum of these points reflects the complexity value of the word.

There are some differences between Turkish and English with regard to phonetic complexity that require a modified IPC scheme for Turkish. The Turkish vowel system has eight monophthongs and no diphthongs ${ }^{2}$. This makes the size of the Turkish vowel system small relative to English. Also, whilst English has 24 agreed consonant sounds, the number of consonants in Turkish is disputable. Some researchers consider that Turkish has 20 consonants (Fidan, 2011; Ergenç \& Bekar-Uzun (2017), while others consider that it has 21 consonants with the soft $\mathrm{g}(<\breve{\mathrm{g}}>)$ as a consonant sound in Turkish (Varol, 2012)._Selen (1979), Ergenç (1989; 1995), Fidan (2011) and Ergenç and Bekar-

\footnotetext{
${ }^{2}$ On the other hand, diphthongs occur in some words because of $<\breve{\mathrm{g}}>$, semi vowel $/ \mathrm{y} /$ and some other borrowed words for Turkish.
} 
Uzun (2017) do not consider $<\breve{g}>$ as a sound in Turkish although it has phonetic functions in the language. Specifically, although $<\breve{\mathrm{g}}>$ is not pronounced, it has two functions in Turkish: (1) vowel-lengthening; and (2) formation of diphthongs. If $<\breve{\mathrm{g}}>$ is written between two vowels with the same acoustic quality or if it precedes a single vowel, then the vowels are pronounced longer; in addition, if $<\breve{\mathrm{g}}>$ occurs between two different vowels, the vowels are diphthongized (Fidan, 2011; Ergenç \& Bekar-Uzun, 2017, ÜnalLogacev, Zygis \& Fuchs, 2019). Ünal-Logacev et al (2019, p.20) even report that $<\breve{\mathrm{g}}>$ "is phonetically manifested in the lengthening of the preceding vowel $(/ \mathrm{V} \breve{g} / \rightarrow[\mathrm{V}:])$ independently of the surrounding vowel environment." In the present study, $<\breve{g}>$ is considered a unit with the functions explained above but is not realized as a phoneme.

In contrast to English, Turkish makes limited use of consonant clusters: The phonotactics of Turkish does not allow syllable-initial consonant clusters. If a cluster occurs at the beginning of a word, two possible procedures apply. These are, adding a vowel in front of the word, and adding a vowel between two consonants. Whilst some of these processes occur in written language, others only occur in spoken language. In (5) two possible word clusters that exemplify these procedures are shown:

(5) (a) stavros [st $\alpha v^{\prime}$ 'əs] $>$ istavroz [Istav' roz] ' cross $^{3}$

(b) tren [tI'ren] 'train'

In example (5a), the original word's consonant cluster/st/ occurs at the beginning of the word. In this case, for Turkish, an [I] vowel precedes the first consonant leading to two syllables instead of one syllable with a cluster. The written and spoken form of the word 'cross' is the same (istavroz). In example (5b) the word is pronounced with an [I] vowel between the consonant cluster in spoken language. In other words, the word 'tren'

\footnotetext{
${ }^{3}$ For more similar examples see Ergenç and Bekar-Uzun (2017, p.273).
} 
is written with a consonant cluster but it is not pronounced as [tren] but as [tI'ren]. Turkish phonotactics allow a limited range of consonant cluster at the end of the words. Some common clusters are -rk (such as Türk [' $\left.\mathrm{t}^{\mathrm{h}} \mathrm{Yrc}\right]$ 'Turk'); -rt (such as dört ['dœrt] 'four'), -nç (such as kıvanç [k $\mathrm{k} \ddot{\mathrm{I}}$ 'vant]] 'pride' and -lk (such as ilk ['Ilc] 'fïrst'). Wordinitial consonant clusters lead to a higher chance of stuttering for children aged 12 years and above and in AWS, whilst word-final consonant clusters do not have an impact on stuttering for any age groups according to the EXPLAN model (Howell, Au-Yeung, Yaruss \& Eldridge, 2006). In general, Turkish differs from English with regard to vocalic and consonantal phonemic systems, word initial consonant clustering and word length. These factors have direct effect of the complexity index (IPC) of a word and result in different complexity levels across English and Turkish.

The original Jakielski (2000) IPC as described in Eldridge (2006) is shown in Table 2, and the Turkish IPC scheme proposed here is given in Table 3. In the Turkish version Factor 4 is eliminated. English words are scored using Table 2 according to the earlier description and the overall word score is the sum over all the factors. Words with higher IPC scores are more difficult to produce, and, therefore, more likely to be stuttered. The procedure is applied for Turkish in a similar way using Table 3.

Tables 2 and 3 about here

Based on the differences between English and Turkish at the levels of morphological typology (analytic vs. agglutinative), phonological structures (syllable onset consonant clustering) and phonemic inventory (smaller Turkish consonant and vowel repertoires), the study aimed to test the hypotheses of the EXPLAN model discussed below. This enabled us to bring in a cross-linguistic dimension to the study of phonetic complexity in stuttering. The current study was intended to address the following questions: 


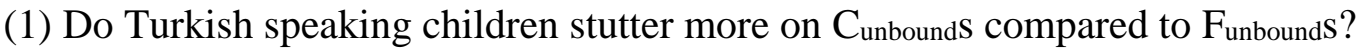

(2) Do Turkish-speaking children stutter more on words with higher Turkish IPC scores?

\section{Materials and Methods}

\section{Participants}

Participants were 21 monolingual children who stuttered (CWS) who had clinical diagnoses from the Kocaeli University Hospital, Speech and Language Therapy Clinic. All participants were diagnosed at the first session by two experienced speech and language therapists based on a detailed clinical interview and the Turkish version of

Stuttering Severity Instrument IV (SSI-4) at the first session (Mutlu, 2014). The 21 (13 boys, 8 girls) Turkish-speaking monolingual CWS were aged between 6.00 and 11 (mean ages $=8,3$ ) years; $\mathrm{SD}=1.65$ ). Children younger than 6 , or older than 11 , years were not included in the study for two reasons. First, the Turkish version of SSI-4 only has normative data for the 6-16 years age range. Second, disfluency types change after age 12 (Howell, 2007). The participants had no other speech or language problem, no history of neurological, psychiatric or hearing disorders, and had not received any therapy for stuttering or learning problems.

Approval of the Ethics Committee of Kocaeli University was obtained before conducting the study and written informed consent was obtained from all the participants.

\section{Instruments}

Stuttering Severity Instrument Version 4: The Turkish version of Stuttering Severity Instrument (SSI-4) (Mutlu, 2014) was administered to all of the participants in order to determine the frequency, duration and observed physical concomitants of stuttering. The original (English) version of SSI-4 was developed to determine the severity of overt features of stuttering (Riley, 2009). It provides a comprehensive picture of overt features of stuttering compared to measures including only the percentage of stuttered syllables 
alone. It is recommended in SSI-4 that more than one speech sample should be used since stuttering varies according to context. Spontaneous speech samples of CWS were collected by a speech and language therapist and the stuttering severity was obtained for all participants. Age, gender and severity (SSI-4) of the participants are given in Table 4.

Table 4 about here

\section{Transcription and scoring}

Speech samples were obtained from the recordings of participants' spontaneous conversations with one of the speech and language therapists acting as a discourse partner. The recordings lasted between 5 and 12 minutes and participants were asked about their daily routines, their favorite books, foods or movies, etc. The first 200 words of each sample were analyzed.

Transcriptions were made by two independent linguists independently. Both linguists were native speakers of Turkish. In the first stage of scoring, all the words in the sample were classified into four categories by the two Turkish speaking native linguists: (i) $\mathrm{F}_{\text {unbound }}(\mathrm{N}=496$ words), (ii) Funbound $+\mathrm{FM}$ (N=239 words), (iii) $\mathrm{C}(\mathrm{N}=1769$ words) and (iv) $\mathrm{C}+\mathrm{FM}$ (N=1699 words). Second, phonetic complexities of words in these classes were scored in accordance with the Turkish IPC scoring system. IPC of Jakielski, Matyasse and Doyle (2006) has not been used in any previous Turkish study. Before reliability measurement started, a guide explaining the classification processes of words and scoring system of IPC was prepared and $10 \%$ of the randomly selected sample data was evaluated independently by the researcher-linguist and the second linguist. As the guide was intended to explain how a word would get one or more points according to 
IPC, phonetic symbols of Turkish sounds for each category of IPC and the definitions of key terms such as C, F, CM, FM, Cunbound, Fbound ...etc. with examples, were included in the guide. Both linguists evaluated the samples in accordance with the guide. Similarly, two independent speech and language therapists rated the moments of stuttering. The percentage of agreement for the identification of moments of stuttering and lexical category were calculated to determine intra-judge and inter-judge reliability (Table 5). Inter-class correlation coefficient was calculated where values range between $0-1(0=$ no agreement, 1 = perfect agreement).

Table 5 about here

\section{Results}

\section{Statistical Analyses}

1. Do Turkish speaking children stutter more on $C_{\text {unbound }}$ compared to $F_{\text {unbounds }}$ ?

A series of Wilcoxon signed rank test (the data were not normally distributed) was used to identify percentage of stuttered word differences in all lexical categories. A $p<0.05$ significance level was adopted. The Wilcoxon signed-rank tests showed that the mean

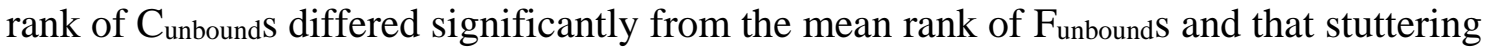
frequency for $\mathrm{C}_{\text {unbounds }}$ was significantly higher than for $\mathrm{F}_{\text {unbounds }} \mathrm{Z}=-2.19, p=.02$.

2. Do Turkish-speaking children stutter more on words with higher Turkish IPC scores?

Related t-tests were used to compare the differences between stuttered and fluent words for each lexical type. The difference between the mean IPC scores of stuttered and nonstuttered words was not significant although the mean IPC scores of the stuttered words were higher than the fluent ones in all categories except for the Funbound + FMs group. The 
mean of the total IPC scores of groups of words separately for stuttered and fluent words are given in Table 6 .

Table 6 about here

The mean percentage of total IPC score of the stuttered words in each lexical category were calculated and compared across lexical categories using Wilcoxon signed rank test. None of the comparisons between pairs of lexical categories was significant as seen in (Table 7). However, in each lexical category, the mean percentage and mean rank was lower in $\mathrm{C}_{\text {unbound }}$ and $\mathrm{F}_{\text {unbound }}$ forms of the words compared to words with FMs.

Table 7 about here

\section{Discussion}

The mean phonetic complexity scores of stuttered words were higher than the mean phonetic complexity scores of fluent words in all lexical categories although the differences were not significant. Direction is consistent with findings in languages like English (Howell et al., 2006), Spanish (Au-Yeung, Gomez \& Howell, 2003) and German (Dworzynski \& Howell, 2004). In these studies it was found that stuttering occurred more on Fs (phonetically less complex) compared to Cs (phonetically more complex) in young CWS, whereas CWS children in the current study stuttered more on $\mathrm{C}_{\text {unbound }}$ compared to Funbound.

Turkish, having agglutinative word structures with inflectional and derivational processes, leads to a very rich morphology. Most of the time morphemes are added and, accordingly, word-length increases. In other words, the different bound morphemes 
added to a root word make it phonetically and syntactically more complex. Compared to the phonetically less complex Funbound all types of Turkish Cs with more suffixes increase the possibility of stuttering in all age ranges (Özdemir, Aydın \& Selvi, 2015).

These results are also consistent with the results reported in languages, e.g. Persian (Vahab et al., 2013) and Japanese (Ujihira, 2011) which also have inflectional endings on Cs. The distinct features of Turkish make it difficult to compare the stuttering moments in Fs and Cs in English. Contrary to Turkish, English Fs often precede Cs. That is, there are few Fs that precede Cs in Turkish; this reduces the opportunities for stalling disfluencies. For this reason, it would predicted that stallings which have a role in facilitating the fluency of children who stutter by preventing them from developing the other stuttering symptoms (e.g., blocks, prolongations etc.) are rarer in Turkish children (Howell, 2010).

The findings of the current study highlight the effect of phonetic complexity on stuttering moments. They also pave the way for crosslinguistic analysis of diverse languages that belong to different morphological typologies with different complexity levels to identify what is potentially universal versus that which is language-specific. The results add more evidence to the constitutional and environmental factors underlying stuttering in different languages. The EXPLAN model builds on the time planning and execution processes take. A linguistically complex segment requires more time to be planned before being executed. In a language such as Turkish that allows for compounding with multi stems and arbitrary length, the possibility for advancing-type stuttering increases. Accordingly, a standardized objective test with appropriate intervention strategies for Turkish-speaking CWS should take into consideration the peculiar linguistic aspects of Turkish. 
Future comparative epidemiological studies are needed to see the spontaneous recovery differences between children from different linguistic backgrounds (Ujihira, 2011).

\section{Limitations of the Study}

Spontaneous speech samples were used in this study. This has many advantages including allowing lengths of the samples in the study to vary and use of phonemes in their repertoires that they ordinarily use. However, some would regard this as a limitation of the study with the lack of control it entails. The second limitation of the study is not controlling material across the speech samples of participants. Future studies with larger samples and a wider age group that controls factors like word length, word frequency, word stress and phonotactic properties might allow for examination of the weighted effects of the phonetic complexity among other lexical factors, and will give chance to generalize the results.

\section{Acknowledgements}

We would like to thank to Prof. Dr. Özgür Aydın, for his valuable comments and to our students (Cansu Pancar, Halime Arığtekin, Melike Topal, Yunus Alperen Öncel) for their help collecting the data.

\section{Declaration of interest statement}

The authors report no conflict of interest 


\section{References}

Acarlar, F. \& Judith J. (2011). Acquisition of Turkish grammatical morphology by children with developmental disorders. International Journal Language and Communication Disorders, 46 (6), 727-738. https://doi.org/10.1111/j.1460$\underline{6984.2011 .00035 . x}$

Al-Tamimi, F., Khamaiseh, Z., \& Howell, P. (2013). Phonetic complexity and stuttering in Arabic. Clinical Linguistics and Phonetics, 27, 874-887. https://doi.org/10.3109/02699206.2013.823242

Au-Yeung, J., Howell, P., \& Pilgrim, L. (1998). Phonological words and stuttering on function words. Journal of Speech, Language, and Hearing Research, 41, 10191030. https://doi.org/10.1044/jslhr.4105.1019

Au-Yeung, J., Gomez, I. V., \& Howell, P. (2003). Exchange of disfluency with age from function to content words in Spanish speakers who stutter. Journal of Speech, Language, and Hearing Research, 46, 754-765. https://doi.org/10.1044/1092$\underline{4388(2003 / 060)}$

Balcı, A. (2012). Biçimbilim II: Sözcük yapısı. In S. Özsoy \& Z. Erk-Emeksiz (Eds.), Genel dilbilim I. (pp. 36-59). Anadolu University Pub.

Bloodstein, O. \& Gantwerk, B. F. (1967). Grammatical function in relation to stuttering in young children. Journal of Speech and Hearing Research, 10, 786-789. https://doi.org/10.1044/jshr.1004.786

Bloodstein, O. \& Grossman, M. (1981). Early stutterings: Some aspects of their form and distribution. Journal of Speech and Hearing Research, 24, 298-302. https://doi.org/10.1044/jshr.2402.298 
Brown, S. F. (1937). The influence of grammatical function on the incidence of stuttering. Journal of Speech Disorders, 207-215. https://doi.org/10.1044/jshd.0204.207

Brown S.F. (1945). The loci of stutterings in the speech sequence. Journal of Speech Disorders, 10, 182-192. https://doi.org/10.1044/jshd.1003.181

Byrd, C.T., Coalson, G.A., Yang, J., \& Moriarty, K. (2017). The effect of phonetic complexity on the speed of single-word productions in adults who do and do not stutter. Journal of communication disorders, 69, 94-105. https://doi.org/10.1016/j.jcomdis.2017.06.009

Chitoran, I. \& A. C. Cohn. (2009). Complexity in phonetics and phonology: Gradience, categoriality, and naturalness. In F. Pellegrino, E. Marsico, I. Chitoran, C. Coupe (Eds.), Approaches to Phonological Complexity. (pp. 21-46). Mouton de Gruyter.

Coalson, G.A., Byrd, C.T., \& Davis, B.L. (2012). The influence of phonetic complexity on stuttered speech. Clinical Linguistics and Phonetics, 26, 646659. https://doi.org/10.3109/02699206.2012.682696

Dayalu, V. N., Kalinowski, J., Stuart, A., Holbert, D., \& Rastatter, M. P. (2002). Stuttering frequency on content and function words in adults who stutter: A concept revisited. Journal of Speech, Language and Hearing Research, 45, 871878. https://doi.org/10.1044/1092-4388(2002/070)

Dworzynski, K. \& Howell, P. (2004). Predicting stuttering from phonetic complexity in German. Journal of Fluency Disorders, $29 . \quad 149-73$. https://doi.org/10.1016/j.jfludis.2004.03.001

Dworzynski K., Howell P., Au-Yeung J., \& Rommel D. (2004). Stuttering on function and content words across age groups of German speakers who stutter. Journal of 
Multilingual Communication Disorders, 2, 81-101. https://doi.org/10.1080/14769670310001625354

Eldridge, K.A. (2006). Phonological complexity and speech disfluency in young children [Unpublished doctoral dissertation]. University of Pittsburg.

Ergenç, İ. (1989). Türkiye Türkçesinin görevsel sesbilimi. Engin Yayınevi.

Ergenç, İ. (1995). Konuşma dili ve Türkçenin söyleyiş sözlüğü. Simurg.

Ergenç, İ. \& Bekar-Uzun, P. (2017). Türkçenin ses dizgesi. Seçkin.

Fidan, D. (2011). Teaching soft $\mathrm{g}(<\breve{\mathrm{g}}>)$ in acquisition of literacy processing. In L. Uzun \& Ü. Bozkurt (Eds.), Theoretical and Applied Researches on Turkish Language Teaching (pp. 101-112). Die Blue Eule Press.

Howell, P. (2004a). Assessment of some contemporary theories of stuttering that apply to spontaneous speech. Contemporary Issues in Communication Science and Disorders, 39, 122-139. https://doi.org/10.1044/cicsd_31_S_123

Howell P. (2004b). Comparison of two ways of defining phonological words for assessing stuttering pattern changes with age in Spanish speakers who stutter. Journal of Multilingual Communication Disorders, 2 (3), 161-186. https://doi.org/10.1080/14769670412331271105.

Howell, P. (2010). Language processing in fluency disorders. In J. Guendouzi, F. Loncke \& M. Williams (Eds). The Handbook on Psycholinguistics and Cognitive Processes, Perspectives on Communication Disorders. (pp. 437-464). Taylor \& Francis.

Howell, P. \& Akande, O. (2005). Simulations of the types of disfluency produced in spontaneous utterances by fluent speakers, and the change in disfluency type seen as speakers who stutter get older. In J. Veronis and E. Campione (Eds.), 
Disfluency in Spontaneous Speech. ISCA Tutorial and Research Workshop. (pp. 93-98).

Howell, P. \& Au-Yeung, J. (2002). The EXPLAN theory of fluency control and the diagnosis of stuttering. In E. Fave (Ed.), Pathology and Therapy of Speech Disorders. Current Issues in Linguistic Theory Series (pp. 74-94). John Benjamins.

Howell, P. \& Au-Yeung. J. (2007). Phonetic Complexity and Stuttering in Spanish. Clinical Linguistics and Phonetics, 21, 111-127. https://doi.org/10.1080/02699200600709511

Howell P, Au-Yeung J, \& Sackin S. (1999). Exchange of stuttering from function words to content words with age. Journal of Speech, Language, and Hearing Research, 42, 345-354. https://doi.org/10.1044/jslhr.4202.345

Howell, P., Au-Yeung, J. \& Sackin S. (2000). Internal structure of content words leading to lifespan differences in phonological difficulty in stuttering. Journal of Fluency Disorders, 25, 1-20. https://doi.org/10.1016/S0094-730X(99)00025-X

Howell, P., Au-Yeung, J., Yaruss, S. J. \& Eldridge, K. (2006). Phonetic difficulty and stuttering in English. Clinical Linguistics and Phonetics, 20, 703-716. https://doi.org/10.1080/02699200500390990

Howell, P. \& Dworzynski, K. (2005). Planning and execution processes in speech control by fluent speakers and speakers who stutter. Journal of Fluency Disorders, 30 (4), 343-354. https://doi.org/10.1016/J.JFLUDIS.2005.09.005

Howell, P. \& Rusbridge, S. (2011). The speech and language characteristics of developmental stuttering in English speakers. In P. Howell \& J. Van Borsel, (Eds). Multilingual Aspects of Fluency Disorders (pp. 93-138). Multilingual Matters. 
Jackielski, K.J. (1998). Motor organization in the acquisition of consonant clusters. [Unpublished Doctoral dissertation]. University of Texas at Austin.

Jakielski, K. (2000). Quantifying phonetic complexity in words: An experimental index. Paper presented at the Annual Child Phonology Conference, Cedar Falls, IA.

Jakielski, K. J., Matyasse, R., \& Doyle, E. N. (2006). Acquisition of phonetic complexity in children 12-36 months of age. In Poster presented at the Annual American Speech-Language-Hearing Association Convention, Miami, FL.

Logan, K. J. (2001). The effect of syntactic complexity upon the speech fluency of adolescents and adults who stutter. Journal of Fluency Disorders, 26, 85106. https://doi.org/10.1016/S0094-730X(01)00093-6

MacNeilage, P. \& Davis, B. (1990). Acquisition of speech production: Frames, then content. In M. Jeannorod (Ed.), Attention and Performance XIII: Motor Representation and Control (pp. 453-476). Lawrence Erlbaum.

Maddieson, I. (2009). Calculating phonological complexity. In Pellegrino, F., Marsico, E., Chitoran, I. \& Coupé, C. (Eds.), Approaches to Phonological Complexity (pp.83-110). Mouton de Gruyter.

Marchal, A. (2011). https://www.phonetik.uni$\underline{\text { muenchen.de/ jmh/lehre/sem/ws1112/viu/Presentations/Marchal.pdf }}$

Mutlu, A. (2014). The Turkish application of stuttering severity instrument between 616-year-old school age children [Unpublished master's thesis]. Gazi University.

Özdemir, R. S., Aydın, A., \& Selvi, S. (2015). The Relationship between Lexical Category and Stuttering Moments in Turkish. Procedia. Social and Behavioral Sciences 193, 351. https://doi.org/10.1016/j.sbspro.2015.03.320 
Riley, G., (2009). The stuttering severity instrument for adults and children (SSI-4) (4th ed.). Austin, TX: PRO-ED.

Selkirk, E. (1984). Phonology and syntax: The relation between sound and structure. MIT Press.

Silverman S.W, \& Bernstein Ratner, N (1997). Syntactic complexity, fluency, and accuracy of sentence imitation in adolescents. Journal of Speech, Language, and Hearing Research, 40, 95-106. https://doi.org/10.1044/jslhr.4001.95

Smith, A. (1999). Stuttering: A unified approach to a multifactorial, dynamic disorder. In N.B. Ratner \& E. C. Healey (Eds.), Stuttering Research and Practice: Bridging the Gap (pp. 27-44). Lawernce Erlbaum.

Smith, M. \& Howell, P. (2013). Stuttering patterns in Japanese and English preschoolaged and school-aged children: as a progress report. Journal of the Phonetic Society of Japan. 17 (2), 83-89. https://doi.org/10.24467/onseikenkyu.17.2_83

Selen, N. (1979). Söyleyiş sesbilimi, akustik sesbilim ve Türkiye Türkçesi. TDK.

Turkish National Corpus. Retrieved from http://www.tnc.org.tr

Ujihira A. (2011). Stuttering in Japanese. In P. Howell \& von Borsel J. (Eds.), Multilingual Aspects of Fluency Disorders (pp. 373-385). Multilingual Matters.

Ünal-Logacev, Ö., Żygis, M., \& Fuchs, S. (2019). Phonetics and phonology of soft 'g' in Turkish. Journal of the International Phonetic Association, 49 (2), 183-206. https://doi.org/10.1017/S0025100317000317

Vahab, M., Zandiyan, A., Falahi, M. H. \& Howell, P. (2013). Lexical category influences in Persian children who stutter. Clinical Linguistics \& Phonetics, 27 (12), 862873. https://doi.org/10.3109/02699206.2013.809792

Varol, M. (2012). The Influence of Turkish Sound System on English Pronunciation [Unpublished doctoral dissertation]. Florida State University. 

Table 1. Lexical categories in Turkish

\begin{tabular}{llll}
\hline & Unbound & & \multicolumn{2}{l}{ Bound } \\
\hline Lexical & Grammatical & Lexical & Grammatical \\
(Content) & (Function) & (Content) & (Function) \\
\hline Nouns & Pronouns & Derivational & Inflectional \\
& & suffixes & suffixes \\
\hline Verbs & Conjunctions & & \\
\hline Adjectives & Determiners & \\
\hline Adverb & Participle & \\
& (postposition) & \\
& & \\
\end{tabular}


Table 2. Categories of Phonological Complexity and Scoring Criteria of Jakielski, (2000) as cited in Eldridge (2006)

\section{Category}

Consonant by place class

Consonant by manner class

\section{One Point for}

Each dorsal

Each fricative, affricate, or liquid

\begin{tabular}{ll}
\hline Singleton consonants by place variegation & Variegation \\
(if any two singleton consonants vary in place, & \\
consider variegated) & \\
\hline Vowel by class & Each rhotic \\
\hline
\end{tabular}

Word shape

Words ending with a consonant

Words $>=3$ syllables

Word length in syllables

Contiguous consonants (cluster)

Each consonant cluster

Cluster by type (when place is different for any

of the contiguous consonants, place is

Each heterorganic cluster

heterorganic) 
Table 3. Phonetic Complexity Scoring of Turkish ${ }^{4}$

Category One Point Each

Consonant by place class $\quad[g, f, k, c, t, j]$

Example: park 'park' ['park] = 1 points

(Because of /k/ sound)

Consonant by manner class

$\left[f, u, v, s, \int, z, z, 3, h, d z, t \int, r, r, l, t\right]$

Example: park 'park' ['park] = 1 points

(Because of /r/ sound)

Singleton consonants by place variegation

If any two singleton consonants vary in

place of articulation, it is considered as

variegated (A word can only get up to 1

point and consonant clusters can't get

point).

Example: park 'park' ['park] $=\mathbf{0}$ points

(Because consonant clusters are not

scored.)

Word shape

Words ending with a consonant

Example: park 'park' ['park] = 1 point

(Because last sound is consonant.)

Word length in syllables

Words $>=3$ syllables

\footnotetext{
${ }^{4}$ Turkish word park 'park' is scored in all categories as an example.
} 
Example: park 'park' ['pork] $=0$ point

(Because there is only one syllable in

the word.)

Contiguous consonants (cluster)

Each consonant cluster (in word final

clusters, if a suffix with a vowel is

added to the word cluster, and if a

vowel is pronounced between

consonant cluster no point is given)

Example: park 'park' ['park] =1 point

(Because of -rk consonant cluster)

Cluster by type (when place is different for any

Each heterorganic cluster (If there is

of the contiguous consonants, place is

place variegation between the

heterorganic)

consonants comprising a cluster, then

it is heterorganic.)

Example: park 'park' ['park] =1 point

(The /rk/ cluster in the word ['park]

moves from the coronal /r/ to the

dorsal /k/) 
Table 4. Gender, age and stuttering severity of the participants in the study

\begin{tabular}{|c|c|c|c|c|c|c|c|}
\hline $\begin{array}{l}\text { Participan } \\
\text { t }\end{array}$ & $\begin{array}{l}\text { Age } \\
\text { (months } \\
\text { ) }\end{array}$ & $\begin{array}{l}\text { Gende } \\
r\end{array}$ & $\begin{array}{l}\text { Severity } \\
\text { (SSI-4) }\end{array}$ & $\begin{array}{l}\text { Participa } \\
\text { nt }\end{array}$ & $\begin{array}{l}\text { Age } \\
\text { (months } \\
\text { ) }\end{array}$ & $\begin{array}{l}\text { Gende } \\
r\end{array}$ & $\begin{array}{l}\text { Severity } \\
\text { (SSI-4) }\end{array}$ \\
\hline 1 & 92 & Girl & severe & 12 & 123 & Boy & mild \\
\hline 2 & 126 & Boy & $\begin{array}{l}\text { moderat } \\
\mathrm{e}\end{array}$ & 13 & 95 & Boy & severe \\
\hline 3 & 100 & Boy & $\begin{array}{l}\text { very } \\
\text { severe }\end{array}$ & 14 & 73 & Boy & mild \\
\hline 4 & 83 & Boy & severe & 15 & 87 & Boy & mild \\
\hline 5 & 94 & Boy & $\begin{array}{l}\text { very } \\
\text { severe }\end{array}$ & 16 & 75 & Girl & $\begin{array}{l}\text { moderat } \\
\mathrm{e}\end{array}$ \\
\hline 6 & 96 & Girl & $\begin{array}{l}\text { very } \\
\text { severe }\end{array}$ & 17 & 72 & Boy & $\begin{array}{l}\text { very } \\
\text { severe }\end{array}$ \\
\hline 7 & 121 & Girl & $\begin{array}{l}\text { moderat } \\
\mathrm{e}\end{array}$ & 18 & 101 & Girl & $\begin{array}{l}\text { moderat } \\
\mathrm{e}\end{array}$ \\
\hline 8 & 109 & Girl & severe & 19 & 72 & Boy & severe \\
\hline 9 & 132 & Girl & mild & 20 & 90 & Boy & mild \\
\hline 10 & 131 & Boy & mild & 21 & 109 & Boy & $\begin{array}{l}\text { moderat } \\
\mathrm{e}\end{array}$ \\
\hline 11 & 121 & Girl & mild & & & & \\
\hline
\end{tabular}


Table 5. Intra-judge and inter-judge reliability agreement for measurement of stuttering severity, moments of stuttering and lexical category identification

\begin{tabular}{llllll}
\hline & $\begin{array}{l}\text { Moments } \\
\text { of } \\
\text { Stuttering }\end{array}$ & C Cunbound & C+ FMs & FunboundS & FunboundS + FMs \\
\hline Intra-judge & 0.98 & 0.96 & 0.99 & 0.98 & 0.94 \\
\hline Inter-judge & 0.95 & 0.94 & 0.99 & 0.96 & 0.96 \\
\hline
\end{tabular}


Table 6. Differences between IPC scores of stuttered and fluent words in each category

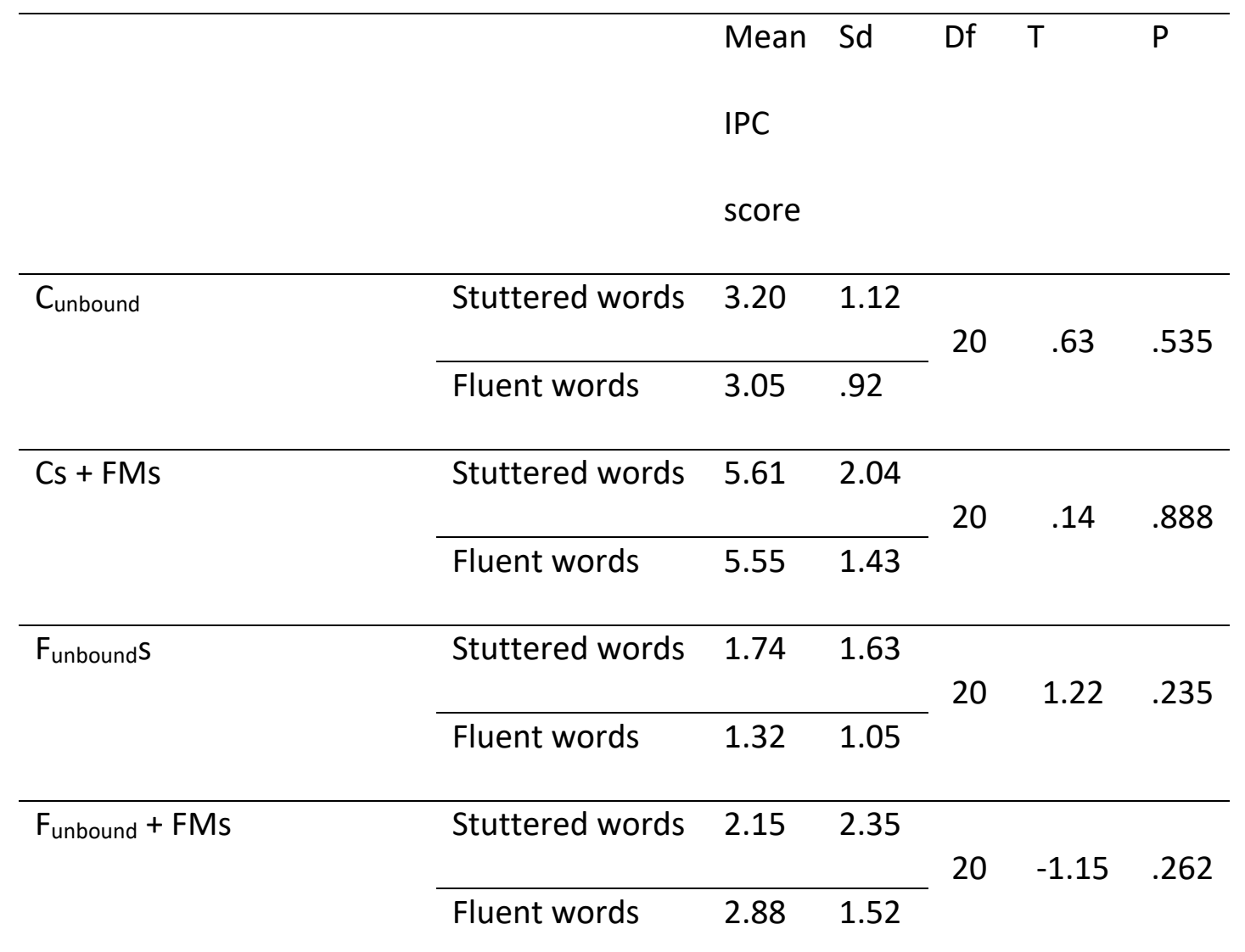


Table 7. Mean percentage of total IPC score of the stuttered words in each lexical category

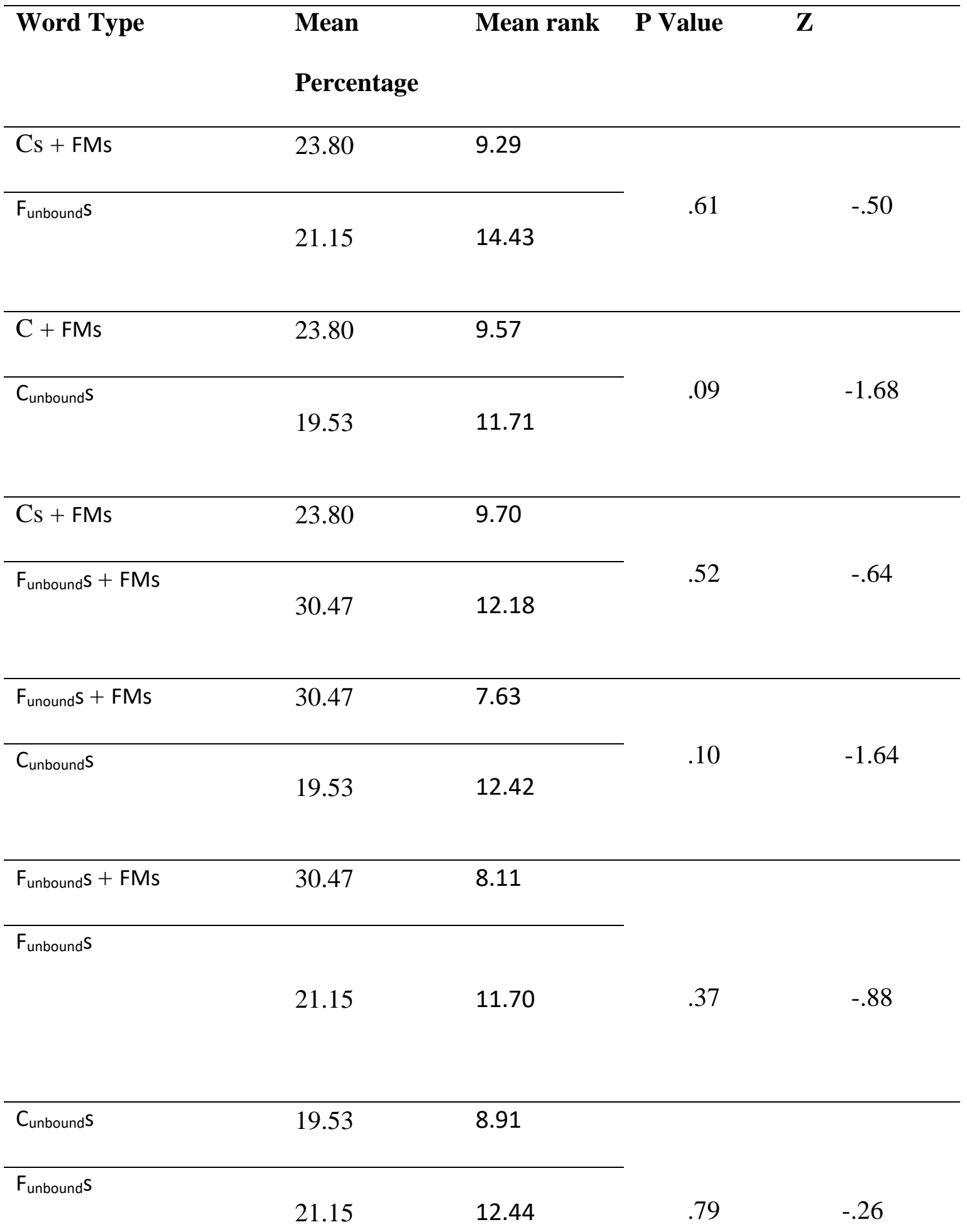


Alpha levels, Means, standard deviations (S.D), and ranges of $A \_F Q$ subscales for all respondents 